\title{
DESKRIPSI KUALITAS DAN KUANTITAS \\ LIMBAH CAIR USAHA LAUNDRY DI KELURAHAN SUMAMPIR KECAMATAN PURWOKERTO UTARA KABUPATEN BANYUMAS TAHUN 2018
}

\author{
Adninda Huda Nisa ${ }^{1)}$, Mela Firdaust ${ }^{2)}$, Bayu Chondro Purnomo ${ }^{3)}$ \\ Jurusan Kesehatan Lingkungan, Politeknik Kesehatan Kemenkes Semarang, \\ Jl. Raya Baturraden KM. 12 Purwokerto, Indonesia
}

\begin{abstract}
Abstrak
[Deskripsi Kualitas dan Kuantitas Limbah Cair Usaha Laundry di Kelurahan Sumampir Kecamatan Purwokerto Utara Kabupaten Banyumas Tahun 2018] Perkembangan usaha laundry di Kelurahan Sumampir yang semakin pesat membuat lingkungan perairan di wilayah tersebut menjadi berbusa dan ditumbuhi mikroalga. Tujuan penelitian untuk mendeskripsikan dan mengetahui kualitas dan kuantitas limbah cair usaha laundry di Kelurahan Sumampir. Jenis penelitian, penelitian deskriptif. Subyek penelitian 9 usaha laundry, parameter yang diukur yaitu kadar phosphate limbah cair, jenis detergen, komposisi detergen, takaran detergen, volume limbah cair, frekuensi pembuangan limbah cair dan cara pengelolaan limbah cair dari usaha laundry. Hasil penelitian 89\% usaha laundry dengan rerata kadar phospate 0,76 mg/L (memenuhi syarat), $11 \%$ usaha laundry dengan kadar phosphate 5,84 mg/L (tidak memenuhi syarat), 67\% usaha laundry menggunakan jenis detergen cair, lunak dan matic top load dan 33\% responden menggunakan jenis detergen bubuk, keras dan matic front load, 44\% responden tidak menggunakan jenis detergen sesuai dengan jenis mesin cucinya. Komposisi detergen yang digunakan oleh usaha laundry yaitu yaitu Total Surfactant 25\%, Antibacterial Agent 0,1 \%, Sodium Alkyl Benzene Sulfonate dan Natrium Karbonat 20\%. Mayoritas takaran detergen yang digunakan usaha laundry yaitu 23 ml. Rerata volume limbah cair yang dihasilkan dari 9 usaha laundry 1038,57 liter/hari. Rerata frekuensi pembuangan limbah cair dari 9 usaha laundry 13 kali/hari dan100\% usaha laundry tidak melakukan pengelolaan limbah cair usaha laundry dan tidak memiliki sarana pengolahan limbah cair. Simpulan, kualitas dan kuantitas limbah cair pada usaha laundry di Kelurahan sumampir beresiko terhadap pencemaran lingkungan.
\end{abstract}

Kata kunci : Kualitas dan Kuantitas; Air Limbah Laundry

\section{Abstract}

[Description of Quality and Quantity Waste Water from Laundry Business in Sumampir Village, North Purwokerto Subdistrict, Banyumas Regency Year 2018] Background The development of laundry business in the increasingly rapid in Sumampir village make the aquatic environment in the region to be foamy and overgrown with microalgae. Research purposes to describe and to know the quality and quantity of waste water of laundry in Sumampir Village. Type of research, descriptive research. The subjects 9 laundry business, parameters measured are phosphate content of waste water, detergent type, detergent composition, detergent dosage, volume of waste water, frequency of waste water disposal and waste water management from laundry business.The results $89 \%$ of laundry business with average phospate $0,76 \mathrm{mg} / \mathrm{L}$ (content appropriate) and $11 \%$ laundry business with phosphate level of $5.84 \mathrm{mg} / \mathrm{L}$ (did not appropriate), 67\% of the laundry business used liquid detergent, soft and matic top load type and 33\% of respondents used powder detergent, hard and matic front load, $44 \%$ of respondents did not use detergents according to the type of washing machine. Detergent composition used by laundry business that is $25 \%$ Total Surfactant, Antibacterial Agent, Sodium Alkyl Benzene Sulfonate and Natrium Carbonate 20\%. The majority of the detergent dosage used by the laundry business is $23 \mathrm{ml}$. The average volume of waste water produced from 9 laundry business 1038.57 liters/day. Average frequency of waste water disposal from 9 laundry business 13 times/day and 100\% laundry business does not manage the waste water and does not have a waste water treatment facilities. Conclusion, the quality and quantity of wastewater at laundry business in Sumampir Village is at risk of environmental pollution.

Keywords : Quality and Quantity; Laundry Waste Water

$\begin{array}{ll}\text { 1) E-mail } & \text { : indaadnindahudanisa@gmail.com } \\ \left.{ }^{2}\right) \text { E-mail } & \text { : melafirdaust.airlangga@gmail.com } \\ \text { 3) E-mail } & \text { : bayu.chondro.purnomo@gmail.com }\end{array}$ 


\section{Pendahuluan}

Air diperlukan dalam kehidupan sehari - hari untuk keperluan minum, mencuci, industri, kegiatan pertanian dan sebagainya, karena air merupakan salah satu sumber daya alam yang memiliki fungsi sangat penting bagi kehidupan dan peri kehidupan manusia, serta untuk memajukan kesejahteraan umum, sehingga dapat menjadi modal dasar dan faktor utama pembangunan (Kementerian Negara Lingkungan Hidup, 2010).

Peraturan Pemerintah Republik Indonesia Nomor 82 Tahun 2001 tentang Pengelolaan Kualitas Air dan Pengendalian Pencemaran Air, menyebutkan bahwa untuk melestarikan fungsi air perlu dilakukan pengelolaan kualitas air dan pengendalian pencemaran air secara bijaksana dengan memperhatikan kepentingan generasi sekarang dan mendatang serta keseimbangan ekologis. Hal tersebut dimaksudkan agar setiap badan air dapat terlindungi dari terjadinya pencemaran air sehingga kualitas air tidak menurun akibat bahan cemaran yang dihasilkan dari aktivitas manusia. Dewasa ini, air justru sering menjadi masalah dan perlu mendapat perhatian yang serius, karena dari segi kualitas dan kuantitas air telah berkurang yang disebabkan oleh pencemaran.

Penyebab terjadinya pencemaran pada air apabila air terkontaminasi dengan bahan pencemar air seperti sampah rumah tangga, sampah limbah industri, sisa sisa pupuk atau pestisida dari daerah, limbah rumah sakit, dan limbah kotoran ternak. Menurut Hammer (M. Rizky J. Balfas, 2015, h.15) frekuensi pencemaran lingkungan perairan yang cukup tinggi disebabkan oleh kegiatan pencucian, sekitar $70 \%$ phosphate berasal dari detergen. Phosphate inilah yang menyebabkan pencemaran dan berdampak buruk bagi kelangsungan hidup biota air serta kesehatan manusia.

Kelurahan Sumampir merupakan pemukiman padat rumah penduduk dengan perkembangan usaha laundry yang semakin tahun, semakin pesat. Dampak dari penggunaan detergen oleh usaha laundry membuat lingkungan perairan di wilayah tersebut menjadi berbusa dan ditumbuhi mikroalga. Hal itu disebabkan limbah dari usaha laundry di dominasi oleh air detergen yang memiliki komposisi senyawa utama Sodium Tripolyphosphate (STPP) dan Alkyl Benzene Sulfonate (ABS), dimana kedua senyawa tersebut sulit terurai secara alamiah di dalam air yang umumnya tidak diolah secara benar ataupun langsung dibuang ke saluran pembungan air dan badan air. Tujuan penelitian ini adalah untuk mendeskripsikan dan mengetahui kualitas dan kuantitas limbah cair usaha laundry di Kelurahan Sumampir.

\section{Bahan Dan Metode}

Disain yang digunakan adalah survey ke usaha laundry di Kelurahan Sumampir, dengan ketentuan pengambilan sampel dilakukan di usaha laundry yang memiliki saluran outlet mesin cuci terpisah dengan saluran black water. Hal ini bertujuan untuk mendapatkan sampel kadar phosphate hanya dari laundry. Didapatkan sebanyak 20 dari 40 usaha laundry yang memiliki saluran outlet mesin cuci terpisah dengan saluran black water, selanjutnya dari 20 usaha laundry didapatkan sebanyak 9 usaha laundry dengan cara purposive sampling yaitu saluran outlet mesin cucinya dapat diakses untuk pengambilan sampel limbah cair laundry. Setelah itu, dilakukan pengambilan sampel limbah cair dari bilasan pertama mesin cuci, bertujuan agar kadar phosphate dapat dideteksi. Kemudian dilakukan pemeriksaan kadar phosphate di Laboratorium Kesehatan Masyarakat Kabupaten Banyumas.

Subyek adalah usaha laundry di Kelurahan Sumampir, Kecamatan Purwokerto Utara, Kabupaten Banyumas yang berjumlah 9 laundry, parameter yang diukur adalah kadar phosphate limbah cair usaha laundry, jenis detergen, komposisi detergen, takaran detergen, volume limbah cair yang dihasilkan, frekuensi pembuangan limbah cair dan cara pengelolaan limbah cair usaha laundry di Kelurahan Sumampir, Kecamatan Purwokerto Utara, Kabupaten Banyumas. Jenis data yang digunakan adalah data umum dan data khusus. Data umum meliputi profil Kelurahan Sumampir, serta profil kondisi usaha laundry di Kelurahan Sumampir, Kecamatan Purwokerto Utara, Kabupaten Banyumas. Data khusus meliputi kadar phosphate, jenis detergen, komposisi detergen, takaran detergen, volume limbah cair yang dihasilkan, frekuensi pembuangan limbah cair dan cara pengelolaan limbah cair.

Sumber data dari penelitian ini adalah data primer dan data sekunder. Data primer diperoleh dari wawancara dengan responden penelitian, pengamatan, pengukuran langsung dan pemeriksaan kadar phosphate di Laboratorium Kesehatan Masyarakat Kabupaten Banyumas. Data sekunder diperoleh dari profil Kelurahan Sumampir, serta buku Surat Keterangan Usaha (SKU) laundry milik Kelurahan Sumampir. Pengumpulan data dilakukan dengan cara observasi, yaitu pengamatan dan pencatatan langsung secara nyata di lapangan, pemeriksaan kadar phosphate di laboratorium. Wawancara yang dilakukan dengan menggunakan kuesioner kepada pemilik serta karyawan usaha laundry di Kelurahan Sumampir, Kecamatan Purwokerto Utara, Kabupaten Banyumas serta Pemeriksaan laboratorium kadar phosphate adalah suatu prosedur pemeriksaan khusus kadar phosphate limbah cair usaha laundry di Laboratorium Kesehatan Masyarakat Kabupaten Banyumas. Instrumen pengumpulan data yang digunakan dalam penelitian ini yaitu kuesioner dan alat ukur fisik berupa indera mata, gelas ukur, alat takar dan satu set alat uji phosphate.

Pengolahan data dilakukan dengan cara editing, yaitu melakukan pengecekan terhadap semua data yang sudah terkumpul untuk menghindari kesalahan. Coding, yaitu mengelompokkan data dan disajikan dalam bentuk tabel untuk memudahkan dalam analisis data. Tabulating, yaitu mengelompokkan data yang sudah terkumpul dalam bentuk tabel. Saving, yaitu 
menyimpan data menyimpan keseluruhan data dari tahap persiapan hingga tahap penyelesaian dalam sebuah dokumen softcopy dan hardcopy.

Analisis data yang digunakan adalah analisis deskriptif yaitu analisis terhadap data yang ada pada tabel kemudian membandingkan dengan Peraturan Menteri Lingkungan Hidup Republik Indonesia Nomor 5 Tahun 2014 tentang baku mutu limbah cair untuk industri sabun, detergen, dan produk - produk minyak nabati.

Etika penelitian yang digunakan adalah Informed Consent (lembar persetujuan), yaitu kesepakatan antara peneliti dengan responden dengan memberikan lembar persetujuan menjadi responden. Jika responden menolak maka peneliti tidak akan memaksa dan harus menghormati hak dari pihak terkait. Anonimity (tanpa nama), yaitu menjaga kerahasiaan dengan peneliti tidak akan mencantumkan nama responden, tetapi responden tersebut diberi kode. Confidentaly (kerahasiaan), yaitu informasi responden dijamin oleh peneliti, hanya sekelompok data tertentu yang akan dilaporkan sebagai data hasil pengukuran.

\section{Hasil Dan Pembahasan}

\section{a. Gambaran Umum}

Data Jumlah Usaha Laundry di Kelurahan Sumampir Berdasarkan buku Surat Keterangan Usaha (SKU) Kelurahan Sumampir tercatat data jumlah usaha laundry dari tahun 2009 hingga 2017. Setiap tahunnya selalu ada penambahan pendirian usaha laundry. Usaha laundry paling banyak didirikan pada tahun 2012 dan paling sedikit didirikan pada tahun 2011 dan 2017 (pada tahun 2017 data jumlah laundry belum tercatat seluruhnya, karena masyarakat setempat yang mendirikan usaha laundry hanya meminta izin pendirian secara lisan RT). Untuk 9 usaha laundry yang dijadikan sebagai tempat pengambilan sampel penelitian paling awal berdiri tahun 2009 dan terakhir berdiri tahun 2017. Rincian jumlah usaha laundry berdasarkan tahun dapat dilihat pada gambar 1 .

\section{Jumlah Usaha Laundry Berdasarkan Tahun}

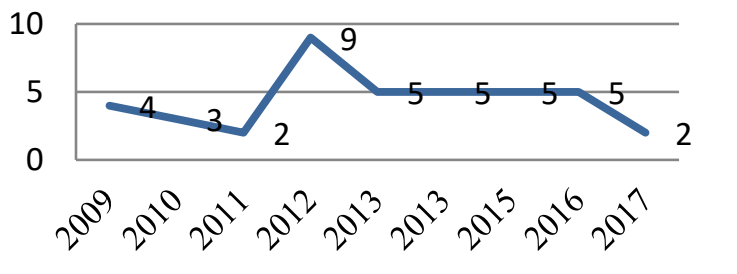

Gambar 1. Grafik Jumlah Usaha Laundry Berdasarkan Tahun

Letak usaha laundry di Kelurahan Sumampir tersebar di jalan Riyanto sebanyak 20 usaha, jalan Jatisari sebanyak 8 usaha, jalan Kenanga sebanyak 2 usaha, jalan Anggrek sebanyak 2 usaha, jalan Serayu sebanyak 1 usaha, Perum Griya Satriya sebanyak 5 usaha dan jalan Flamboyan sebanyak 2 usaha.

Untuk 9 usaha laundry yang dijadikan sebagai tempat pengambilan sampel penelitian terletak di jalan Riyanto sebanyak 3 usaha, jalan Jatisari sebanyak 2 usaha, jalan Anggrek sebanyak 1 usaha, jalan Serayu sebanyak 1 usaha, Perum Griya Satriya sebanyak 1 usaha dan jalan Flamboyan sebanyak 1 usaha. Dari data tersebut, menunjukkan bahwa usaha laundry terbanyak terletak di jalan Riyanto. Berikut ini merupakan rincian jumlah usaha laundry berdasarkan letak, dapat dilihat pada grafik 2 .

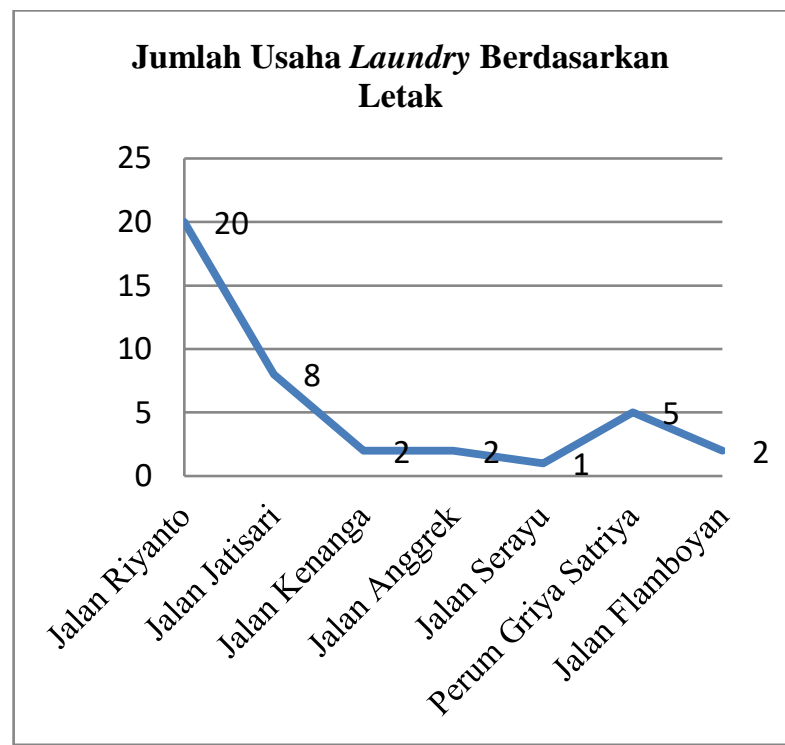

Gambar 2. Grafik Jumlah Usaha Laundry Berdasarkan Letak

\section{Kondisi Usaha Laundry}

Sebagian besar usaha laundry yang beroperasi telah berizin atau mendapat Surat Keterangan Usaha (SKU) dari Kelurahan Sumampir. Berdasarkan hasil penelitian, 3 diantara 9 responden penelitian hanya meminta izin membuka usaha laundry secara lisan kepada RT. Bangunan usaha laundry di Kelurahan Sumampir memiliki 2 tipe, yaitu terpisah dengan rumah pemilik dan menyatu dengan rumah pemilik atau ruko (rumah toko). Bangunan usaha laundry milik 9 responden penelitian semuanya termasuk ke dalam tipe ruko. Sumber air yang digunakan usaha laundry di Kelurahan Sumampir untuk kegiatan laundry berasal dari PDAM dan sumur. Detergen yang digunakan berasal dari sumber resmi yang sering di jumpai di pasaran. Saluran outlet untuk pembuangan limbah cair laundry di Kelurahan Sumampir ada 2 tipe, yaitu :

1) Saluran outlet mesin cuci menyatu dengan saluran black water.

2) Saluran outlet mesin cuci terpisah dengan saluran black water.

Untuk saluran buangan limbah cair laundry dari outlet mesin cuci di usaha laundry milik 9 responden penelitian semua dipisahkan dengan saluran black 
water dan dapat diakses untuk pengambilan sampel limbah cair laundry.

\section{b. Gambaran Khusus}

Kadar Phosphate $\left(\mathrm{PO}_{4}\right)$

Pengambilan sampel limbah cair laundry dilaksanakan pada tanggal 29 Desember 2017 s.d 3 Januari 2018. Tujuan pengambilan sampel limbah

cair laundry adalah untuk mengetahui kadar phosphate $\left(\mathrm{PO}_{4}\right)$ pada limbah cair usaha laundry yang berada di Kelurahan Sumampir. Pemeriksaan sampel limbah cair dilakukan di Laboratorium Kesehatan Masyarakat Kabupaten Banyumas. Rincian hasil pemeriksaan kadar phosphate $\left(\mathrm{PO}_{4}\right)$ sampel limbah cair usaha laundry 9 responden penelitian dapat dilihat pada tabel 1 .

Tabel 1. Kadar Phosphate $\left(\mathrm{PO}_{4}\right)$

\begin{tabular}{|c|c|c|c|}
\hline $\begin{array}{c}\text { Kode } \\
\text { Respon } \\
\text { den } \\
\text { Peneli } \\
\text { tian }\end{array}$ & $\begin{array}{c}\text { Kadar } \\
\text { Phosphate } \\
\text { (mg/L) }\end{array}$ & Standar *) & Keterangan \\
\hline R1 & 0,73 & \multirow{9}{*}{$2 \mathrm{mg} / \mathrm{L}$} & MS \\
\hline R2 & 0,60 & & $\mathrm{MS}$ \\
\hline R3 & 0,74 & & MS \\
\hline $\mathrm{R} 4$ & 0,64 & & MS \\
\hline R5 & 1,35 & & MS \\
\hline R6 & 5,84 & & TMS \\
\hline R7 & 1,17 & & MS \\
\hline $\mathrm{R} 8$ & 0,45 & & MS \\
\hline R9 & 0,39 & & MS \\
\hline
\end{tabular}

Keterangan :

*) : Peraturan Menteri Lingkungan Hidup Republik Indonesia No 5 Tahun 2014

MS : Memenuhi Syarat

TMS : Tidak Memenuhi Syarat

Tabel 1 menunjukkan bahwa kadar phosphate terendah yaitu $0,39 \mathrm{mg} / \mathrm{L}$ berasal dari sampel limbah cair R2. Kadar phosphate tertinggi yaitu 5,84 mg/L berasal dari sampel limbah cair R6. Kadar phosphate tertinggi telah melebihi standar baku mutu lingkungan Peraturan Menteri Lingkungan Hidup Republik Indonesia No 5 Tahun 2014 yaitu 2 mg/L. Rerata kadar phosphate limbah cair yang didapatkan dari sampel limbah cair 9 usaha laundry yaitu 1,32 mg/L.

\section{Jenis Detergen}

Data jenis detergen didapatkan dari label jenis detergen pada kemasan detergen yang digunakan oleh 9 responden penelitian. Sebanyak $67 \%$ responden penelitian menggunakan jenis detergen cair, lunak dan matic top load dan $33 \%$ responden menggunakan jenis detergen bubuk, keras dan matic front load.

Berdasarkan hasil wawancara, 6 responden penelitian (R1, R2, R3, R4, R8, R9) pengguna detergen cair memilih detergen tersebut karena karakteristik detergen cair mudah larut dalam air sehingga lebih mudah menyerap pada serat pakaian dan tidak meninggalkan residu di mesin cuci.
Sementara, 3 responden penelitian lainnya (R5, R6, R7) memilih detergen bubuk karena karakteristik detergen bubuk yang memiliki alkalinitas dan enzimatis tinggi, sehingga daya bersihnya kuat dan dapat membersihkan kotoran yang membandel.

Kemudian, keenam responden (R1, R2, R3, R4, R8, R9) menggunakan detergen yang memiliki kandungan gugus aktif bersifat lunak. Pada hasil pemeriksaan kadar phosphate keenam responden tersebut mendapatkan rerata kadar phosphate 0,76 mg/L. Menurut Mamay Maslahat, dkk (2010), detergen lunak dinilai lebih ramah lingkungan dikarenakan rantai karbon tidak bercabang, melainkan memanjang sehingga dapat diuraikan oleh mikroorganisme. Salah satu mikroorganisme yang dapat menguraikan senyawa yang ada pada detergen lunak adalah Pseudomonas aeruginosa. Sementara, ketiga responden lainnya (R5, R6, R7) menggunakan detergen yang memiliki kandungan gugus aktif bersifat keras. Pada hasil pemeriksaan kadar phosphate ketiga responden tersebut mendapatkan rerata kadar phosphate tinggi dengan rerata 2,78 mg/L. Menurut Amylia Aisyahwalsiah (2010), ABS tidak dapat terurai oleh bakteri pengurai, sehingga dapat mencemari lingkungan. Berikut ini merupakan rincian jenis detergen yang digunakan oleh 9 responden penelitian.

Tabel 2. Jenis Detergen

\begin{tabular}{|c|c|c|c|}
\hline Kode & & is Detergen & \\
\hline $\begin{array}{l}\text { Respon } \\
\text { den } \\
\text { Peneli } \\
\text { tian }\end{array}$ & $\begin{array}{c}\text { Berdasar } \\
\text { kan } \\
\text { Bentuk } \\
\text { Fisiknya }\end{array}$ & $\begin{array}{c}\text { Berdasarkan } \\
\text { Kandungan } \\
\text { Gugus } \\
\text { Aktifnya }\end{array}$ & $\begin{array}{c}\text { Berdasarkan Cara } \\
\text { Pencuciannya }\end{array}$ \\
\hline R1 & Cair & Lunak & Matic Top Load \\
\hline $\mathrm{R} 2$ & Cair & Lunak & Matic Top Load \\
\hline $\mathrm{R} 3$ & Cair & Lunak & Matic Top Load \\
\hline R4 & Cair & Lunak & Matic Top Load \\
\hline $\mathrm{R} 5$ & Padat & Keras & Matic Front Load \\
\hline R6 & Padat & Keras & Matic Front Load \\
\hline $\mathrm{R} 7$ & Padat & Keras & Matic Front Load \\
\hline R8 & Cair & Lunak & Matic Top Load \\
\hline R9 & Cair & Lunak & Matic Top Load \\
\hline
\end{tabular}

Sebanyak $44 \%$ responden tidak menggunakan detergen sesuai dengan jenis mesin cucinya. Penggunaan jenis detergen yang sesuai dengan jenis mesin cuci akan mempermudah sistem kerja mesin cuci dan sebaliknya, jika penggunaan jenis detergen tidak sesuai dengan jenis mesin cuci maka akan menghambat sistem kerja dan dapat merusak mesin cuci. (Tofik Mujahidin, 2014). rincian kesesuaian penggunaan jenis detergen matic top load dan matic front load dengan jenis mesin cuci yang digunakan oleh responden penelitian. Dapat dilihat pada tabel 5.1 dan tabel 3. 
Tabel 3. Kesesuain antara Jenis Detergen (Matic Top Load) dengan Jenis Mesin Cuci yang Digunakan Responden Penelitian

\begin{tabular}{|c|c|}
\hline $\begin{array}{l}\text { Kode Responden } \\
\text { Penelitian }\end{array}$ & Takaran Detergen \\
\hline $\begin{array}{l}\text { R1, R2, } \\
\text { R3, R4 }\end{array}$ & $23 \mathrm{ml} / 3 \mathrm{~kg}$ linen \\
\hline R5 & $110 \mathrm{gr} / 4 \mathrm{~kg}$ linen \\
\hline R6 & $120 \mathrm{gr} / 3 \mathrm{~kg}$ linen \\
\hline R7 & $106 \mathrm{gr} / 4 \mathrm{~kg}$ linen \\
\hline $\mathrm{R} 8$ & $23 \mathrm{ml} / 4 \mathrm{~kg}$ linen \\
\hline R9 & $23 \mathrm{ml} / 4,5 \mathrm{~kg}$ linen \\
\hline
\end{tabular}

Berdasarkan tabel 3, responden dengan kode R9 tidak menggunakan jenis detergen yang sesuai dengan jenis mesin cuci.

Tabel 4. Kesesuain antara Jenis Detergen (Matic Front Load) dengan Jenis Mesin Cuci yang Digunakan Responden Penelitian

\begin{tabular}{|c|c|c|c|}
\hline $\begin{array}{c}\text { Kode } \\
\text { Respon } \\
\text { den } \\
\text { Penelitian }\end{array}$ & $\begin{array}{c}\text { Jenis } \\
\text { Detergen }\end{array}$ & $\begin{array}{c}\text { Jenis Mesin } \\
\text { Cuci }\end{array}$ & Keterangan \\
\hline R1 & $\begin{array}{c}\text { Matic } \\
\text { Top Load }\end{array}$ & $\begin{array}{c}\text { Mesin Cuci } \\
\text { Bukaan } \\
\text { Atas }\end{array}$ & Sesuai \\
\hline R2 & $\begin{array}{c}\text { Matic } \\
\text { Top Load }\end{array}$ & $\begin{array}{c}\text { Mesin Cuci } \\
\text { Bukaan } \\
\text { Atas }\end{array}$ & Sesuai \\
\hline R3 & $\begin{array}{c}\text { Matic } \\
\text { Top Load }\end{array}$ & $\begin{array}{c}\text { Mesin Cuci } \\
\text { Bukaan } \\
\text { Atas }\end{array}$ & Sesuai \\
\hline $\mathrm{R} 4$ & $\begin{array}{c}\text { Matic } \\
\text { Top Load }\end{array}$ & $\begin{array}{c}\text { Mesin Cuci } \\
\text { Bukaan } \\
\text { Atas }\end{array}$ & Sesuai \\
\hline $\mathrm{R} 8$ & $\begin{array}{c}\text { Matic } \\
\text { Top Load }\end{array}$ & $\begin{array}{c}\text { Mesin Cuci } \\
\text { Bukaan } \\
\text { Atas }\end{array}$ & Sesuai \\
\hline R9 & $\begin{array}{c}\text { Matic } \\
\text { Top Load }\end{array}$ & $\begin{array}{c}\text { Mesin Cuci } \\
\text { Bukaan } \\
\text { Bawah }\end{array}$ & $\begin{array}{l}\text { Tidak } \\
\text { Sesuai }\end{array}$ \\
\hline
\end{tabular}

Berdasarkan tabel 4 , ketiga responden penelitian tidak menggunakan jenis detergen yang sesuai dengan jenis mesin cuci.

\section{Komposisi Detergen}

Data komposisi didapatkan dengan melihat label kemasan detergen yang digunakan oleh 9 responden penelitian. Untuk R1, R2, R3, R4, R8 dan R9 menggunakan detergen merk A, R5 menggunakan detergen merk B, R6 menggunakan detergen merk C dan R7 menggunakan detergen merk D. Data komposisi dapat dilihat pada tabel 5 .
Tabel 5. Komposisi Detergen

\begin{tabular}{cl}
\hline $\begin{array}{c}\text { Kode } \\
\text { Responden } \\
\text { Penelitian }\end{array}$ & \multicolumn{1}{c}{$\begin{array}{c}\text { Komposisi Detergen } \\
\text { (Bahan Aktif) }\end{array}$} \\
\hline $\begin{array}{c}\mathrm{R} 1, \mathrm{R} 2, \mathrm{R} 3, \\
\mathrm{R} 4, \mathrm{R} 8, \mathrm{R} 9 .\end{array}$ & $\begin{array}{l}\text { Total Surfactant 25\% } \\
\text { Antibacterial Agent } 0,1 \%\end{array}$ \\
\hline $\mathrm{R} 5$ & $\begin{array}{l}\text { 15\% Sodium Alkyl Benzene } \\
\text { Sulfonate (ABS) }\end{array}$ \\
\hline $\mathrm{R} 6$ & $\begin{array}{l}\text { Sodium Alkyl Benzene } \\
\text { Sulfonate (ABS) }\end{array}$ \\
\hline $\mathrm{R} 7$ & $\begin{array}{l}\text { 16\% Surfactan utama, 20\% } \\
\text { Natrium Karbonat (builder) }\end{array}$ \\
\hline
\end{tabular}

Berdasarkan tabel 5, sebanyak $67 \%$ responden menggunakan detergen tanpa bahan aktif ABS atau builder dan $33 \%$ responden penelitian menggunakan detergen dengan bahan aktif ABS atau builder.

\section{Takaran Detergen}

Data takaran detergen didapatkan dari label berat bersih (netto) pada kemasan detergen dan juga dengan melakukan pengukuran menggunakan sendok takar dan timbangan. Untuk R1, R2, R3, R4, R8 dan R9 menggunakan 1 sachet detergen cair dengan label netto yang tertera pada kemasan $23 \mathrm{ml}$. R5 menggunakan detergen bubuk 2 sendok takar dengan berat timbangan $110 \mathrm{gr}$, R6 menggunakan detergen bubuk 3 sendok takar dengan berat timbangan $120 \mathrm{gr}$, R7 menggunakan detergen bubuk 2 sachet dengan netto 106 gr. Di bawah ini merupakan rincian takaran detergen yang digunakan oleh 9 responden penelitian.

Tabel 6. Takaran Detergen.

Tabel 6 diatas menunjukkan bahwa mayoritas responden penelitian menggunakan detergen dengan takaran sebanyak $23 \mathrm{ml}$, tetapi untuk berat linennya berbeda. Kemudian, R6 menggunakan detergen dengan takaran terbanyak yaitu 120 gr untuk berat linen $3 \mathrm{~kg}$.

Volume Limbah Cair

Volume limbah cair pada pembilasan pertama

\begin{tabular}{cccc}
\hline $\begin{array}{c}\text { Kode } \\
\text { Responden } \\
\text { Penelitian }\end{array}$ & $\begin{array}{c}\text { Jenis } \\
\text { Deter } \\
\text { Gen }\end{array}$ & Jenis Mesin Cuci & $\begin{array}{c}\text { Kete } \\
\text { rangan }\end{array}$ \\
\hline R5 & $\begin{array}{c}\text { Matic } \\
\text { Front } \\
\text { Load }\end{array}$ & $\begin{array}{c}\text { Mesin Cuci Bukaan } \\
\text { Atas }\end{array}$ & $\begin{array}{c}\text { Tidak } \\
\text { Sesuai }\end{array}$ \\
& Matic & Mesin Cuci Bukaan & Tidak \\
R6 & Atas & Sesuai \\
& Load & & \\
\hline R7 & Matic & Mesin Cuci Bukaan & Tidak \\
& Front & Atas & Sesuai \\
& Load & & \\
\hline
\end{tabular}

dipengaruhi oleh jenis mesin cuci, kapasitas mesin cuci dan berat linen yang dicuci. Volume limbah cair usaha laundry per hari didapatkan dari perhitungan volume limbah cair pada pembilasan pertama 
dikalikan dengan teknik pencucian pada mesin cuci dan frekuensi pencucian per hari. Berikut ini merupakan data volume limbah cair pada pembilasan pertama dan data volume limbah cair yang dihasilkan per hari oleh masing - masing usaha laundry milik 9 responden penelitian. Rincian volume limbah cair pada pembilasan pertama dan volume limbah cair yang dihasilkan per hari dapat dilihat pada tabel 7 dan tabel 8 .

Tabel 7. Volume Limbah Cair pada Pembilasan Pertama

\begin{tabular}{ccccc}
\hline $\begin{array}{c}\text { Kode } \\
\text { Responden } \\
\text { Penelitian }\end{array}$ & $\begin{array}{c}\text { Jenis } \\
\text { Mesin } \\
\text { Cuci } \\
\text { (Tabung) }\end{array}$ & $\begin{array}{c}\text { Kapasitas Berat } \\
\text { Cuci } \\
\text { (Kg) }\end{array}$ & $\begin{array}{c}\text { Linen } \\
\text { Setiap } \\
1 \times \\
\text { Cuci } \\
\text { Limbah Cair } \\
\text { pada }\end{array}$ & $\begin{array}{c}\text { Vembilasan 1 } \\
\text { (Liter) }\end{array}$ \\
\hline R1 & 1 & 6,5 & 3 & 72 \\
\hline R2 & 2 & 8 & 6 & 100 \\
\hline R3 & 1 & 6 & 3 & 70 \\
\hline R4 & 1 & 6 & 3 & 70 \\
\hline R5 & 1 & 6,5 & 3 & 72 \\
\hline R6 & 1 & 11 & 9 & 120 \\
\hline R7 & 1 & 8 & 4 & 90 \\
\hline R8 & 2 & 6,5 & 4 & 78 \\
\hline R9 & 1 & 6,5 & 4,5 & 78 \\
\hline
\end{tabular}

Tabel $7 \mathrm{di}$ atas menunjukkan mayoritas responden penelitian menggunakan jenis mesin cuci 1 tabung. R6 memiliki kapasitas mesin cuci terbesar yaitu $11 \mathrm{~kg}$ sehingga dapat memuat linen $9 \mathrm{~kg}$ untuk $1 \mathrm{x}$ cuci dan menghasilkan volume limbah cair pada pembilasan pertama 120 liter. R3 dan R4 memiliki kapasitas mesin cuci terkecil yaitu $6 \mathrm{~kg}$ sehingga hanya dapat memuat $6 \mathrm{~kg}$ linen untuk $1 \mathrm{x}$ cuci dan menghasilkan volume limbah cair 70 liter.

Kemudian, tabel 8 menunjukkan rerata volume limbah cair pada pembilasan pertama 83 liter, rerata teknik pencucian 2 kali, rerata frekuensi pencucian per hari 5 kali dan rerata volume limbah cair per hari dari 9 usaha laundry milik responden penelitian 1038,6 liter/hari. Berikut ini merupakan tabel 8.

Tabel 8. Volume Limbah Cair

$\begin{array}{cccc}\text { Kode } & \text { Volume } & \text { TeknikFrekuensi } & \text { Volume } \\ \text { Respon } & \text { Limbah } & \text { Pencu Pencucian } & \text { Limbah } \\ \text { den } & \text { Cair pada } & \text { cian Per Hari } & \text { Cair Per }\end{array}$
PenelitianPembilasan (Kali) (Kali) Hari

\begin{tabular}{ccccc} 
& 1 (Liter) & & & (Liter/Hari) \\
\hline R1 & 72 & 3 & 5 & 1080 \\
\hline R2 & 100 & 3 & 5 & 1500 \\
\hline R3 & 70 & 2 & 5 & 700 \\
\hline R4 & 70 & 2 & 5 & 700 \\
\hline R5 & 72 & 3 & 7 & 1080 \\
\hline R6 & 120 & 3 & 6 & 2160 \\
\hline R7 & 90 & 2 & 5 & 900 \\
\hline R8 & 78 & 2 & 5 & 780 \\
\hline R9 & 78 & 2 & 5 & 780 \\
\hline Rata-Rata & 83 & 2 & 5 & 1038,6 \\
\hline & & & &
\end{tabular}

Menurut I Ketut Muliartha (2004), semakin besar volume limbah cair usaha laundry maka kandungan bahan pencemar juga semakin besar. Semakin banyak limbah cair yang dibuang ke lingkungan, maka beban adaptasi lingkungan semakin sulit. Jika lingkungan tidak dapat melakukan pemurnian kembali maka dimungkinkan Kelurahan Sumampir akan tercemar.

\section{Frekuensi Pembuangan Limbah Cair}

Frekuensi pembuangan limbah cair dipengaruhi frekuensi pencucian per hari dan teknik pencucian dari mesin cuci. Semakin banyak frekuensi pencucian per hari dan teknik pencucian dari mesin cuci maka semakin banyak pula frekuensi pembuangan limbah cair pada usaha laundry dan sebaliknya. Oleh karena itu, frekuensi pembuangan limbah cair usaha laundry dapat dihitung dari perkalian antara frekuensi pencucian perhari dengan teknik pencucian pada mesin cuci.

Pada tabel 9 menunjukkan rerata frekuensi pencucian 5 kali, rerata teknik pencucian 2 kali yaitu cuci dan bilas dan rerata frekuensi pembuangan limbah cair dari 9 usaha laundry milik responden penelitian sebanyak 13 kali/hari. Frekuensi pembuangan limbah cair terbanyak adalah R5 yaitu 21 kali/hari. Menurut I Ketut Muliartha (2004), semakin banyak frekuensi pembuangan limbah maka beban pengolahan akan semakin tinggi. Frekuensi pembuangan limbah cair yang secara terus menerus akan lebih berpengaruh terhadap lingkungan dibandingkan dengan membuang limbah secara periodik walau konsentrasi pencemar sama. Berikut ini merupakan rincian frekuensi pembuangan limbah cair dari 9 usaha laundry milik responden penelitian, dapat dilihat pada tabel 9.

Tabel 9. Frekuensi Pembuangan Limbah Cair

Kode Frekuensi Teknik Frekensi

RespondenPencucianPencucian Pembuangan

Penelitian (Kali)

Limbah Cair

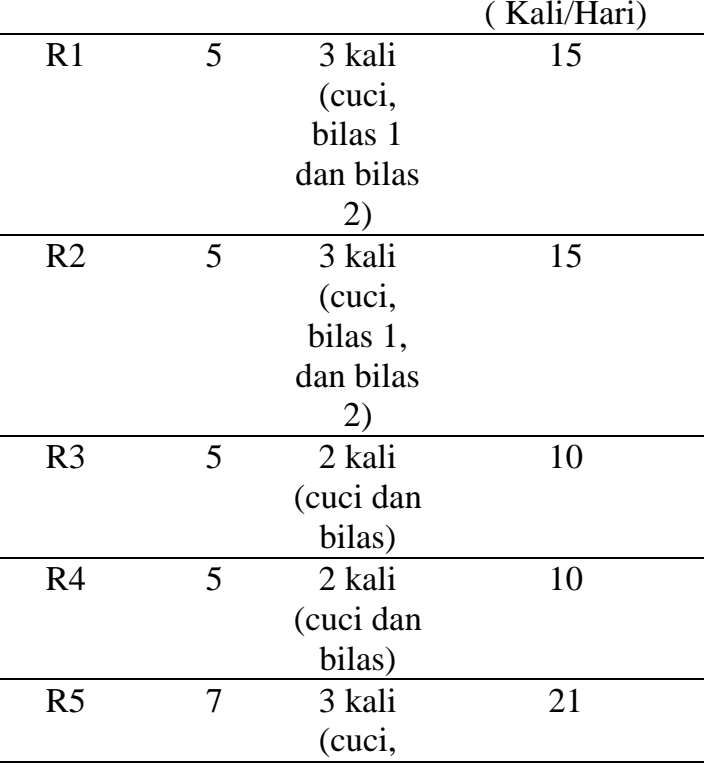




\begin{tabular}{|c|c|c|c|}
\hline \multirow{3}{*}{\multicolumn{3}{|c|}{$\begin{array}{l}\text { Kode Frekuensi Teknik } \\
\text { RespondenPencucianPencucian } \\
\text { Penelitian (Kali) }\end{array}$}} & \multirow{3}{*}{$\begin{array}{c}\text { Frekensi } \\
\text { Pembuangan } \\
\text { Limbah Cair } \\
\text { ( Kali/Hari) }\end{array}$} \\
\hline & & & \\
\hline & & & \\
\hline \multicolumn{4}{|c|}{$\begin{array}{c}\text { bilas } 1, \\
\text { dan bilas } \\
\text { 2) }\end{array}$} \\
\hline R6 & 6 & $\begin{array}{c}3 \text { kali } \\
\text { (cuci, } \\
\text { bilas } 1, \\
\text { dan bilas } \\
\text { 2) }\end{array}$ & 18 \\
\hline R7 & 5 & $\begin{array}{c}2 \text { kali } \\
\text { (cuci dan } \\
\text { bilas) }\end{array}$ & 10 \\
\hline R8 & 5 & $\begin{array}{c}2 \text { kali } \\
\text { (cuci dan } \\
\text { bilas) }\end{array}$ & 10 \\
\hline R9 & 5 & $\begin{array}{c}2 \text { kali } \\
\text { (cuci dan } \\
\text { bilas) }\end{array}$ & 10 \\
\hline Rata-Rata & 5 kali & $\begin{array}{c}2 \text { kali } \\
\text { (cuci dan } \\
\text { bilas) } \\
\end{array}$ & 13 \\
\hline
\end{tabular}

Cara Pengelolaan Limbah Cair

Berdasarkan hasil penelitian, $9(100 \%)$ responden penelitian tidak melakukan pengelolaan limbah cair usaha laundry milik masing - masing dan tidak memiliki sarana pengelolaan limbah cair usaha laundry. Sebanyak 8 (89\%) usaha laundry langsung membuang limbah cairnya ke badan air dan hanya 1 (11\%) usaha laundry yang membuang limbah cairnya ke septic tank. Tabel cara pengelolaan limbah cair usaha laundry milik 9 responden penelitian, dapat dilihat pada tabel 10 .

Tabel 10. Cara Pengelolaan Limbah Cair

\begin{tabular}{|c|c|c|c|}
\hline $\begin{array}{c}\text { Kode } \\
\text { Responden } \\
\text { Penelitian }\end{array}$ & kelola & $\begin{array}{c}\text { Tidak } \\
\text { aikelola }\end{array}$ & $\begin{array}{l}\text { Keterangan } \\
\text { Pembuangan } \\
\text { Limbah Cair }\end{array}$ \\
\hline R1 & - & $\sqrt{ }$ & Sungai kecil \\
\hline $\mathrm{R} 2$ & - & $\sqrt{ }$ & Sungai kecil \\
\hline R3 & - & $\sqrt{ }$ & Selokan \\
\hline R4 & - & $\sqrt{ }$ & Sungai kecil \\
\hline R5 & - & $\sqrt{ }$ & Selokan \\
\hline R6 & - & $\sqrt{ }$ & Selokan \\
\hline R7 & - & $\sqrt{ }$ & Sungai kecil \\
\hline $\mathrm{R} 8$ & - & $\sqrt{ }$ & Sungai kecil \\
\hline R9 & - & $\sqrt{ }$ & Septic tank \\
\hline
\end{tabular}

Terkait Undang - undang No. 32 tahun 2009 tentang Perlindungan dan Pengelolaan Lingkungan Hidup disebutkan bahwa setiap usaha dan/atau kegiatan yang tidak termasuk dalam kategori berdampak penting (wajib AMDAL) dan kegiatan mikro dan kecil yang tidak memiliki UKL-UPL wajib membuat surat penyertaan kesanggupan pengelolaan dan pemantauan lingkungan hidup, maka 8 responden penelitian belum memenuhi persyaratan undang undang tersebut.

Alasan responden penelitian tidak memiliki sarana pengolahan limbah cair laundry dikarenakan biaya mahal, sedangkan pendapatan dari usaha laundry hanya cukup untuk memenuhi kebutuhan sehari-hari. Sebagian pengusaha laundry sudah menyadari bahwa pengolahan limbah cair laundry sangat penting. Peraturan di Kabupaten Banyumas belum sampai membahas usaha mikro. Dinas Lingkungan Hidup telah merencanakan penertiban resiko pencemaran lingkungan yang diakibatkan oleh usaha yang menggunakan detergen, namun pengawasan usaha mikro memang belum dilakukan secara maksimal. Ketersediaan pembuatan sarana pengolahan limbah akan dilaksanakan apabila ada tuntutan dari pemerintah.

\section{Penutup}

Berdasarkan hasil penelitian tentang Deskripsi Kualitas dan Kuantitas Limbah Cair Usaha Laundry di Kelurahan Sumampir Kecamatan Purwokerto Utara Kabupaten Banyumas Tahun 2018 dapat diambil kesimpulan bahwa sebanyak $89 \%$ usaha laundry mendapatkan rerata kadar phospate $0,76 \mathrm{mg} / \mathrm{L}$ dan memenuhi syarat, $11 \%$ usaha laundry mendapatkan kadar phosphate $5,84 \mathrm{mg} / \mathrm{L}$ dan tidak memenuhi syarat sesuai dengan Peraturan Menteri Lingkungan Hidup Republik Indonesia No 5 Tahun 2014 yaitu 2 $\mathrm{mg} / \mathrm{L}$. Sebanyak $67 \%$ usaha laundry menggunakan jenis detergen cair, lunak dan matic top load dan $33 \%$ responden menggunakan jenis detergen bubuk, keras dan matic front load.

Sebanyak $44 \%$ responden tidak menggunakan detergen sesuai dengan jenis mesin cucinya. Komposisi detergen yang digunakan oleh usaha laundry yaitu yaitu Total Surfactant 25\%, Antibacterial Agent 0,1 \%, Sodium Alkyl Benzene Sulfonate (ABS) dan Natrium Karbonat $20 \%$. Mayoritas takaran detergen yang digunakan usaha laundry yaitu $23 \mathrm{ml}$. Rerata volume limbah cair yang dihasilkan dari 9 usaha laundry 1038,57 liter/hari. Rerata frekuensi pembuangan limbah cair dari 9 usaha laundry 13 kali/hari. Sebanyak 100\% usaha laundry tidak melakukan pengelolaan limbah cair usaha laundry dan tidak memiliki sarana pengolahan limbah cair.

Kualitas dan kuantitas limbah cair pada usaha laundry di Kelurahan Sumampir beresiko terhadap pencemaran lingkungan. Sebaiknya, pengusaha laundry menggunakan detergen yang ramah lingkungan (bahan aktif non ABS atau non STPP dan yang mencantumkan persentase kandungan bahan aktifnya), membuat sarana pengolahan air limbah sederhana. Dinas Lingkungan Hidup mengawasi pengolahan limbah cair dan melakukan pemeriksaan laboratorium limbah cair usaha laundry. 


\section{Daftar Pustaka}

Amylia Aisyahwalsiah. (2010). Efektivitas Penurunan Kadar Dodesil Benzene Sulfonate (DBS) dari Limbah Detergen yang Diolah dengan Lumpur Aktif. Jurnal Kimia. Bali : Universitas Udayana, diakses pada tanggal 14 September 2017

Arifin. (2008). Metode Pengolahan Deterjen. Madiun: Radionuklida

Asyar M Aidil. (2015). Bab 2 Tinjauan Pustaka. Sumatera Utara: USU, diakses pada tanggal 3 Oktober 2017

Badan Standardisasi Nasional. (2008). SNI 6989.59:2008 Tentang Air dan Limbah Cair - Bagian 59 : Metode pengambilan contoh Limbah Cair. Jakarta: BSN

Ervina Hermawati, dkk. (2005). Fitoremidiasi Limbah Detergen Menggunakan Kayu Apu (Pistia stratiotes L.) dan Genjer (Limnocharis flava L.). Surakarta: UNS, diakses pada tanggal 7 Mei 2018

Fardiaz, Srikandi. (1992). Polusi Air dan Udara. Yogyakarta: Penerbit Kanisius, diakses pada tangal 7 April 2018

Imrotul Ngulya. (2016). Komparasi Penurunan Kadar Phosphate dengan Media Adsorben Arang Sekam Padi dan Tanah Lempung Modifikasi Pada Limbah Cair di Industri Laundry "R" Tahun 2016. Yogyakarta: Politeknik Kesehatan Kemenkes Semarang Jurusan Kesehatan Lingkungan Purwokerto, diakses pada tanggal 7 April 2018

Kementerian Lingkungan Hidup Republik Indonesia. (2014). Peraturan Menteri Lingkungan Hidup Republik Indonesia Nomor 5 Tahun 2014. Jakarta

Kementerian Lingkungan Hidup Republik Indonesia. (2009). Undang - undang No. 32 Tahun 2009 Tentang Perlindungan dan Pengelolaan Lingkungan Hidup. Jakarta

Kementerian Republik Indonesia. (2001). Peraturan Pemerintah Republik Indonesia Nomor 82 Tahun 2001 Tentang Pengelolaan Kualitas Air dan Pengendalian Pencemaran Air. Jakarta
Ketut Swarjana, I. (2015). Metodologi Penelitian Kesehatan (Edisi Revisi). Yogyakarta: Penerbit Andi

Makhrajani Majid, dkk. (2017). "Efektivitas Penggunaan Karbon Aktif pada Penurunan Kadar Phosphate Limbah Cair Usaha Laundry di Kota Pare Pare Sulawesi Selatan" ISBN : 978- 979-3812-41-0, diakses pada tanggal 9 Oktober 2017

Mamay Maslahat, dkk. (2010). Potensi Bakteri Pseudomonas Aeruginosa pada Proses Biodegradasi Alkil Benzena Sulfonat Linear (LAS) dalam Tiga Jenis Detergen Komersial. Bogor: Universitas Nusa Bangsa Bogor

Rendika Ferri. (2015). Beginilah IPAL buatan BLH Yogya untuk Menyaring Limbah Laundry.Yogyakarta: TribunJogja.com, diakses pada tanggal 28 April 2018

Sri Widya Astuti dan Mersi Suriani Sinaga. (2015). Pengolahan Limbah Laundry Menggunakan Metode Biosand Filter untuk Mendegradasi Phosphate. Medan Universtitas Sumatera Utara

Sisyanreswari, Hadinta dkk. (2014). Penurunan TSS, COD, dan Phosphate pada Limbah Laundry Menggunakan Koagulan Tawas dan Media Zeolit. Semarang: UNDIP, diakses pada tanggal 19 Oktober 2017

Suharto. (2011). Limbah Kimia dalam Pencemaran Udara dan Air. Yogyakarta: Penerbit ANDI

Tofik Mujahidin. (2014). Pengelolaan Limbah Cair Pada Usaha Laundry Di Kelurahan Grendeng, Kecamatan Purwokerto Utara, Kabupaten Banyumas Tahun 2014. Purwokerto: Politeknik Kesehatan Kemenkes Semarang Jurusan Kesehatan Lingkungan Purwokerto

Tri Cahyono. (2018). Panduan Penulisan Tugas Akhir. Purwokerto: Politeknik Kesehatan Kemenkes Semarang Jurusan Kesehatan Lingkungan Purwokerto

Yuli Prastiwi, dkk. (2012). "Uji Toksisitas Limbah Cair Laundry Sebelum dan Sesudah Diolah dengan Tawas dan Karbon Aktif terhadap Bioindikator (Cyprinuscarpio L)”. Semarang: UNDIP Jurusan Teknik Lingkungan. diakses pada tanggal 5 Oktober 2017 
Washing Factory. (2018). Fungsi Detergen Matic untuk Mesin Cuci. Malang. at https://www.kaskus.co.id/showpost/5a810d b21a997548118b4569/1/fungsi detergenmatic-untuk-mesin-cuci, diakses pada tanggal 19 April 2018
Zainul Ikhwan. (2015). "Efektifitas Bio Sorben Keladi, Enceng Gondok dan Batang Pisang pada Kandungan Phosphate Limbah Laundry", Vol. 10, No. 1. Hal 45-51. Padang : Universitas Andalas Jurusan Kesehatan Masyarakat. 